\title{
Visual marking: The effects of irrelevant changes on preview search
}

\author{
DERRICK G. WATSON \\ University of Warwick, Coventry, England \\ and \\ GLYN W. HUMPHREYS \\ University of Birmingham, Birmingham, England
}

\begin{abstract}
Visual search is facilitated when participants receive a preview of half of the distractors before presentation of the second distractor set (Watson \& Humphreys, 1997). In seven experiments, we examined the effects of irrelevant change on this preview benefit. Experiments $1-4$ showed that the benefit was not disrupted by the abrupt appearance of irrelevant distractors during the preview period unless they were the same color as the new items. However, blinking off-and-on irrelevant distractors that were present at the start of the preview period disrupted the preview benefit irrespective of their feature overlap with other items (Experiments 5-7). The data are consistent with the inhibition of old stimuli (visual marking) via a location-based template along with an anticipatory feature-based set for new stimuli.
\end{abstract}

The capacity limitations of the visual system are clearly demonstrated by a variety of experimental phenomena including change blindness (e.g., O'Regan, Rensink, \& Clark, 1999; Simons, 1996; Simons \& Levin, 1997, 1998), inattentional blindness (e.g., Mack \& Rock, 1998), and the difficulty of detecting relatively complex targets (e.g., Treisman \& Gelade, 1980). These limitations highlight the importance of having mechanisms that prioritize the order in which visual information is processed if behavior is to be efficient. Historically, research on visual selection has focused heavily on space-based selection in which attention is viewed as a spotlight that enhances the representation of stimuli in a particular 2- or 3-dimensional space (e.g., Downing \& Pinker, 1985; Treisman \& Gelade, 1980). However, recent work has shown that time of appearance can also be used as an effective selection cue. For example, participants are able to effectively ignore old stimuli and restrict their search to a set of new stimuli that appear at a particular point in time (Watson \& Humphreys, 1997, 1998; for an overview, see Watson, Humphreys, \& Olivers, 2003).

Watson and Humphreys (1997) investigated temporal selection, using a modification of the visual search paradigm. Typically, in visual search tasks participants indicate the presence or absence of a specified target among a varying number of distractors. A common finding is

This work was supported by grants from the Economic and Social Research Council and the Medical Research Council, U.K. We thank Tom Carr, Roger Remington, Tram Neil, and Kimron Shapiro for valuable comments and suggestions. Correspondence concerning this article should be addressed to D. G. Watson, Department of Psychology, University of Warwick, Coventry, CV4 7AL, England. (e-mail: d.g.watson@ warwick.ac.uk). that if the target differs from the distractors by a unique feature (a single-feature search task), response times (RTs) do not differ as a function of display size, suggesting parallel detection over the field. In contrast, if the target is defined by a combination of two or more features (a conjunction search task), RTs increase with display size, and absent-to-present slope ratios approach 2:1 (e.g., Treisman \& Gelade, 1980). Generally, search becomes more difficult as the similarity between the target and distractors increases and as the display becomes less homogeneous (e.g., Duncan \& Humphreys, 1989, 1992; Wolfe, 1998). Watson and Humphreys (1997) presented a "preview" condition in which one set of distractors from a conjunction search display (green Hs) was presented (previewed) for 1,000 msec before the remaining new items were added (blue A distractors and a blue $\mathrm{H}$ target, when present). Search in this condition was more efficient (there were shallower search slopes) than when all the items were presented simultaneously (a full-element, conjunction baseline). Indeed, search was equivalent to when the second set of blue letters was presented alone (a half-element, single-feature baseline). This demonstrated that, in the preview condition, participants were able to restrict their search to the new items, ignoring the initial (old) set of stimuli.

\section{Visual Marking}

Watson and Humphreys (1997) proposed that selection was facilitated by the active (top-down) inhibition of old items already in the field - a process they called visual marking. They proposed that the intention to ignore old items resulted in the development of a goal state that initialized and maintained an inhibitory template, which was used to deprioritize old distractors in search 
(see also Humphreys, Watson, \& Jolicœur, 2002, for evidence of dissociable setup vs. maintenance components of the template). For stationary stimuli, Watson and Humphreys (1997) proposed that the template specifies the locations of old items and coordinates the application of inhibition to those stimulus positions. This is consistent with the evidence on the inhibition of probe dots at the location of old distractors (Olivers \& Humphreys, 2002; Watson \& Humphreys, 2000). The net effect of any suppression of old items is that the selection of new items is prioritized. For example, due to the old items being inhibited, the new stimuli enjoy a higher signal-tonoise ratio within a detection system than would otherwise be the case. Furthermore, the number of intentional templates that can be simultaneously maintained may be limited, so that marking becomes less efficient when observers engage in a secondary task while the old items are present (Humphreys, Watson, \& Jolicœur, 2002; Watson \& Humphreys, 1997).

\section{Visual Marking and Visual Change}

Despite visual marking's being under top-down control, certain bottom-up changes at the locations of old distractors coincident with the onset of the new items abolish the preview benefit. Whether or not changes are disruptive to the preview benefit reflects their likely behavioral significance. Watson and Humphreys (2002) examined the effects of luminance, shape, and color changes to the old items. Shape changes completely removed the preview benefit even when there were no overall luminance changes at the locations of the old items. In contrast, luminance changes alone or isoluminant color changes were not disruptive. Watson and Humphreys (2002) argued that shape changes were likely to be behaviorally relevant for selection. In a real-world example, a hunter might be attempting to ignore an old animal, to optimize detection of a newly appearing prey. Any change of shape of the old animal could be important, since it could signal a significant change in its direction of approach. It may be important to "reset" attention under those circumstances, in order to select the old animal.

Luminance or color changes, on the other hand, are more likely the result of changes in general lighting or illumination conditions and would therefore be less relevant for future or current behavior. This is also supported by studies on the effects of occlusion on preview search. Kunar, Smith, Humphreys, and Watson (2003) report data showing no effect of transient stimulus changes on the preview benefit if old items move behind occluders. In contrast, performance is greatly disrupted if equivalent transient changes cannot be attributed to occlusion (e.g., blinking the old items off and then on again, when the new items appear). Maintaining marking across occlusion would be helpful for selection whether irrelevant objects or the observer moved in a cluttered scene.

In the present study, we again assessed the effect of display changes on the preview benefit. However, in con- trast to Watson and Humphreys (2002), here the changes were not to or at the locations of the old items. Rather, we assessed the effect of irrelevant changes occurring in the scene at nondistractor locations on our ability to continue to ignore old items already in the field.

In Experiments 1-4, we assessed the effects of the abrupt appearance of irrelevant stimuli (disks), as a function of their feature similarity with other items in the display, on participants' ability to continue to ignore previously displayed old distractors. From an ecological perspective, it may be adaptive to reprioritize ignored stimuli if they change shape. However, it would not be adaptive to reprioritize old ignored stimuli because of irrelevant changes in other parts of the scene. Nevertheless, evidence suggests that abrupt luminance onsets can capture attention automatically even when they are irrelevant to the present task (e.g., Theeuwes, Kramer, Hahn, \& Irwin, 1998; Yantis \& Jonides, 1984). This may be particularly likely too, if observers attempt to prioritize selection for new onsets (Folk, Remington, \& Johnston, 1992; Folk, Remington, and Wright, 1994). Related to this, O'Regan et al. (1999) showed that irrelevant onsets, analogous to "mud splashes" on a windscreen, were effective in reducing observers' ability to detect changes in a scene occurring at other locations. Here, it is assumed that the (irrelevant) transient mud splashes draw attentional resources, resulting in a reduced ability to detect other (relevant) changes in the scene.

In relation to the present work, if irrelevant onset stimuli capture attention, they may take resources away from the task of inhibiting the old items. This would then result in the old (to-be-ignored) stimuli competing for attention with any newly presented items, thus yielding a reduced preview benefit. Consistent with this possibility, prior studies demonstrate that the preview benefit is weaker when attention is consumed by a dual task when the preview display is present (Humphreys, Watson, \& Jolicœur, 2002; Watson \& Humphreys, 1997). Hence, if irrelevant stimuli presented during the preview attract attention, we would expect the preview benefit to be lessened.

In Experiments 5-7, we examined the effect of changing irrelevant stimuli that were initially displayed with the old items in the field. It is possible that all items present at the start of the preview become incorporated into a representation that is inhibited, to prioritize selection of new items. In that case, transient changes to any part of that representation could reset the inhibition. This can be linked to the notion of a "nexus" representation proposed by Rensink in relation to change blindness. Rensink (2000) suggested that "proto-objects" are constructed from low-level visual processing. Focused attention then acts to link the proto-objects into a temporally stable object representation called a nexus. The nexus has bidirectional links with the proto-objects, such that any change to a proto-object is fed back to the nexus where it can be detected. In the absence of unique transient signals, changes to other objects not represented in or by the 
nexus remain undetected. In a similar way, Watson and Humphreys (1997) proposed that a template acts to coordinate the inhibition of old items in visual marking, with bidirectional links to the locations of the old items. A change to an old item might then feed back to the template in order to modulate inhibition at that location. Inhibition could be reduced if a transient change feeds back to reset the template, at least if that change cannot be attributed to occlusion (cf. Kunar, Smith, et al., 2003). Accordingly, in Experiments 5-7, we assessed whether changes to irrelevant items that may have been encoded into the inhibitory template would impact the preview benefit.

In summary, as detailed earlier, changes to old preview stimuli cause those items to recompete for selection (e.g., because the inhibition is reset). In contrast, the present work aimed to assess the impact of abrupt display changes that were not related to the locations of either old or new search stimuli. Specifically, we aimed to assess whether the preview benefit would be disrupted when (1) new irrelevant stimuli were added to preview displays, and (2) irrelevant stimuli that appeared with the initial preview were altered. These conditions should allow us to specify in more detail the underlying functional architecture of time-based visual selection and its ecological value.

\section{EXPERIMENT 1 \\ Red Irrelevant Onsets Appear Just Before the Search Display}

In Experiment 1, we set out to determine whether the preview benefit would be disrupted by irrelevant changes (multiple abrupt onsets) occurring in the field just before the second set of (search) stimuli was added. As in previous studies (e.g., Watson \& Humphreys, 1997), there were three main conditions: a preview condition in which one set of distractors was presented $950 \mathrm{msec}$ before the new items, a single-feature baseline consisting of just the new items from the preview condition, and a conjunction baseline consisting of all the search items presented simultaneously. The baselines served to test whether search in the preview condition was as efficient as when (1) only the new items appeared (single-feature baseline), or (2) all the items in the final display were searched (the conjunction baseline).

To assess the effects of irrelevant onsets on performance, red disks (which shared neither shape nor color with the new stimuli) were presented $200 \mathrm{msec}$ before the second set of items (blue As and a blue H target, when present) was presented. The two baselines also had red disks presented $200 \mathrm{msec}$ before the final search display in order to equate any general attentional disruption caused by the abrupt onset of the red disks (Yantis \& Jonides, 1984). If the red disks attract attention, they may disrupt inhibition of the old items, thus reducing the preview benefit.

\section{Method}

Participants. There were 12 participants ( 3 males, 9 females), aged 18-22 years $(M=19.4)$. All were undergraduate students at the University of Birmingham with self-reported normal or correctedto-normal visual acuity, and they participated for payment.

Stimuli and Apparatus. A $120-\mathrm{MHz}$ Pentium-based PC presented the displays and recorded all response times (RTs) and participant responses. Displays were presented on a 15 -in. SVGA monitor $\left(\right.$ visible diagonal $\left.=360 \mathrm{~mm}\left[33.4^{\circ}\right]\right)$ at a resolution of $640 \times$ 480 pixels. Displays were generated by custom programs written in Turbo Pascal. The computer monitor was placed at eye level and was viewed from a distance of approximately $60 \mathrm{~cm}$, although no formal means was used to restrict head movements.

The target was a light blue $\mathrm{H}$, and the distractors were light blue As, green Hs, and red disks. The letter stimuli were created by illuminating segments of a box-figure 8 and measured $4 \mathrm{~mm}\left(0.38^{\circ}\right)$ in width $\times 8 \mathrm{~mm}\left(0.76^{\circ}\right)$ in height, and the red disks were $5 \mathrm{~mm}$ $\left(0.48^{\circ}\right)$ in diameter. Each search display was created by positioning the stimuli randomly into the cells of an invisible $10 \times 10$ matrix. The horizontal and vertical distances between the centers of each cell were $12 \mathrm{~mm}\left(1.15^{\circ}\right)$. In the conjunction baseline and preview conditions, the display size was 4,8 , or 16 items. In addition, the display contained red disks. The number of red disks was always equal to the total number of blue items. The single-feature baseline was the same as the conjunction baseline, except that the green distractors were not displayed. The target was present on half of the trials.

Design and Procedure. A trial in the preview condition consisted of a blank screen $(500 \mathrm{msec})$ followed by a white central fixation $\operatorname{dot}\left(1 \mathrm{~mm} \times 1 \mathrm{~mm}\left[0.1^{\circ} \times 0.1^{\circ}\right]\right)$ for $1,000 \mathrm{msec}$. Randomly positioned green $\mathrm{H}$ distractors were then added to the display, after $750 \mathrm{msec}$ an equal number of red disks was added, and $200 \mathrm{msec}$ later the blue items were added. Thus, the green items were presented alone for $750 \mathrm{msec}$, after which red disks were added, followed by the blue items, which would contain the blue $\mathrm{H}$ target, when present.

In the conjunction baseline, red disks appeared after the fixation cross, and after $200 \mathrm{msec}$ the search display (blue A and green $\mathrm{H}$ distractors and a blue $\mathrm{H}$ target, when present) was added. The singlefeature condition was the same as the conjunction baseline, except that the green $\mathrm{H}$ distractors were not displayed. At the start of the experimental session, the three conditions were explained and demonstrated to the participants. Each participant then completed one block of 120 trials for each of the three conditions. Each block contained an equal combination of target-present/absent trials at each of the display sizes. Trial order was randomized within a block, and block order was completely counterbalanced across participants. A practice block consisting of 30 trials was run immediately before each experimental block.

\section{Results}

Figure 1 shows the RTs as a function of target presence, display size, and condition. Search slopes and percentage errors are displayed in Tables 1 and 2. The data were analyzed by comparing the preview condition with each baseline. For comparison with the single-feature baseline, the display size for the preview condition corresponded to the number of new items that were present. For comparisons with the conjunction baseline, the display size corresponded to the total number of items in the final search display (old plus new items, in the preview condition). If the old items can be fully ignored in the preview condition, search slopes in the preview condition should not differ from the single-feature baseline, 




(B) Present

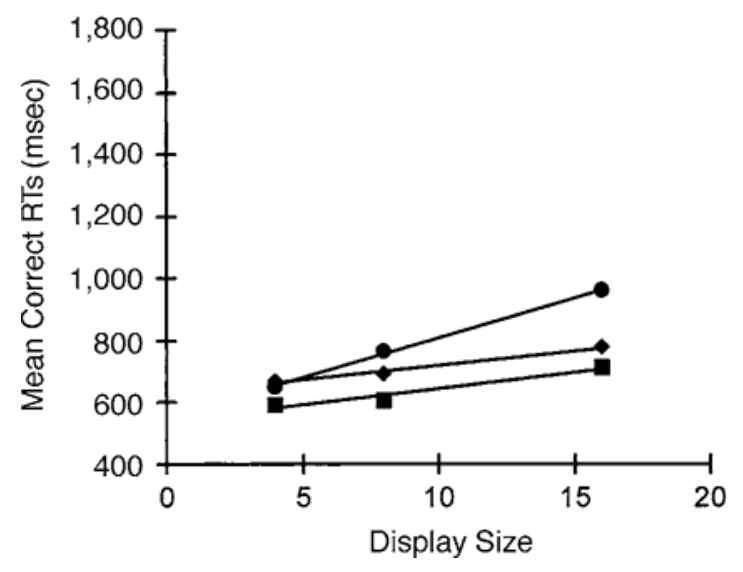

Figure 1. Mean correct response times (RTs) for Experiment 1 as a function of target presence, display size, and condition.

and they should be more efficient than in the conjunction baseline. In contrast, if the old previewed items cannot be ignored, the opposite should occur (preview slopes should be greater than the single-feature baseline slopes and not differ from the conjunction baseline slopes). ${ }^{1}$

\section{Single-Feature Versus Preview}

Reaction times. Mean correct RTs were calculated for each cell of the design for individual participants, with RTs less than $200 \mathrm{msec}$ treated as errors. All three main effects proved significant; RTs were shorter on present trials than on absent trials $\left[F(1,11)=32.65, M S_{\mathrm{e}}=\right.$ 26,634, $p<.001]$, RTs increased with display size $\left[F(2,22)=56.06, M S_{\mathrm{e}}=11,464, p<.001\right]$ and RTs were shorter overall in the single-feature baseline $\left[F(1,11)=18.64, M S_{\mathrm{e}}=20,504, p=.001\right]$. However, of most interest was the lack of a significant display size $\times$ condition interaction $\left[F(2,22)=1.08, M S_{\mathrm{e}}=5,688, p=\right.$ $.357]$, or three-way interaction $\left[F(2,22)=2.56, M S_{\mathrm{e}}=\right.$ $4,439, p=.1]$; this indicates that search efficiency in the preview condition did not differ statistically from that in the single-feature baseline. Of less interest was a significant target $\times$ display size interaction $[F(2,22)=$ $\left.24.45, M S_{\mathrm{e}}=5,922, p<.001\right]$, and the target $\times$ condition interaction was also borderline significant $[F(1,11)=$ 4.78, $\left.M S_{\mathrm{e}}=5,853, p=.051\right]$. RTs increased more with display size on absent trials than on present trials, and there was a greater difference between absent and present RTs in the preview condition. In the last case, participants may have been more cautious in responding absent when there were more stimuli present.

Errors. The mean percentage errors were analyzed in the same way as the RT data. There was a significant target $\times$ display size interaction $\left[F(2,22)=5.60, M S_{\mathrm{e}}=\right.$ $13.684, p=.011]$ and a significant target $\times$ condition interaction $\left[F(1,11)=6.40, M S_{\mathrm{e}}=6.944, p<.05\right]$. Errors tended to increase on present trials and decrease on absent trials as a function of display size. Also in the preview condition, there were more errors on present trials than on absent trials whereas for the single-feature condition the reverse held. Importantly, there was no condition $\times$ display size interaction. Thus, the RT search functions were not compromised by a speed-accuracy tradeoff. No other main effects or interactions approached significance.

\section{Conjunction Versus Preview}

Reaction times. All three main effects were significant; RTs were shorter on present trials than on absent

Table 1

Search Slopes (Milliseconds/Item) for Experiments 1-7

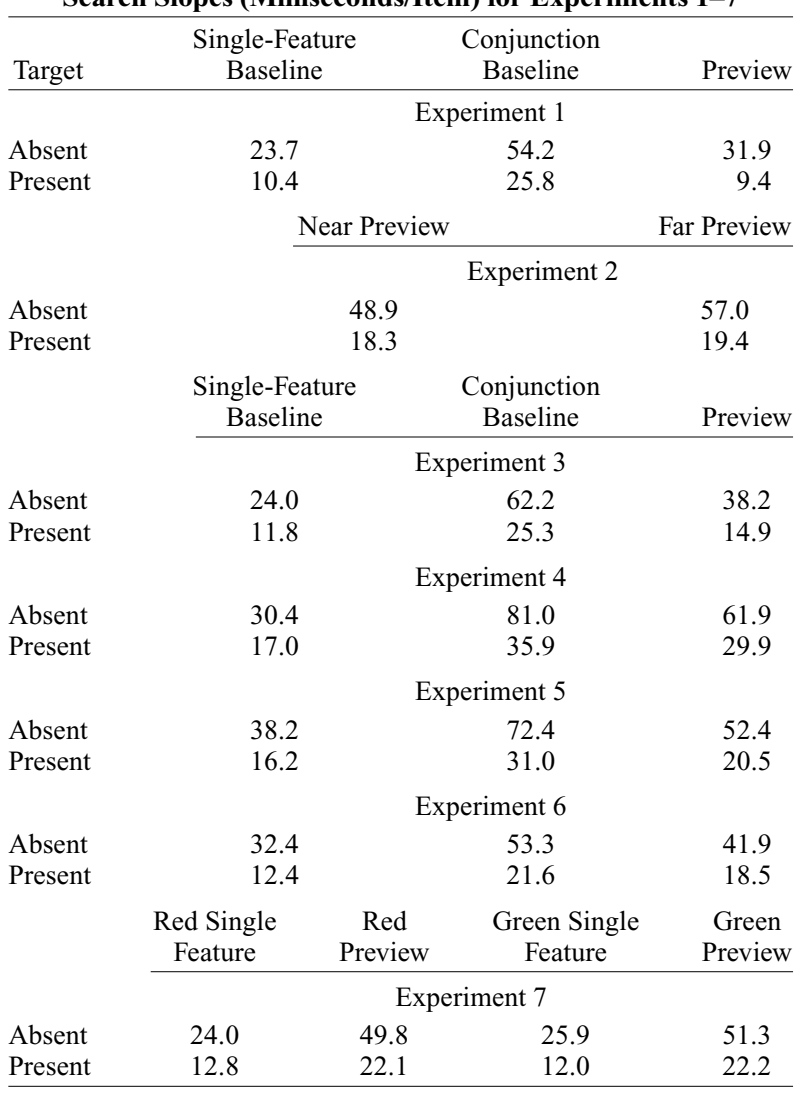


Table 2

Percentages of Errors for Experiments 1-7

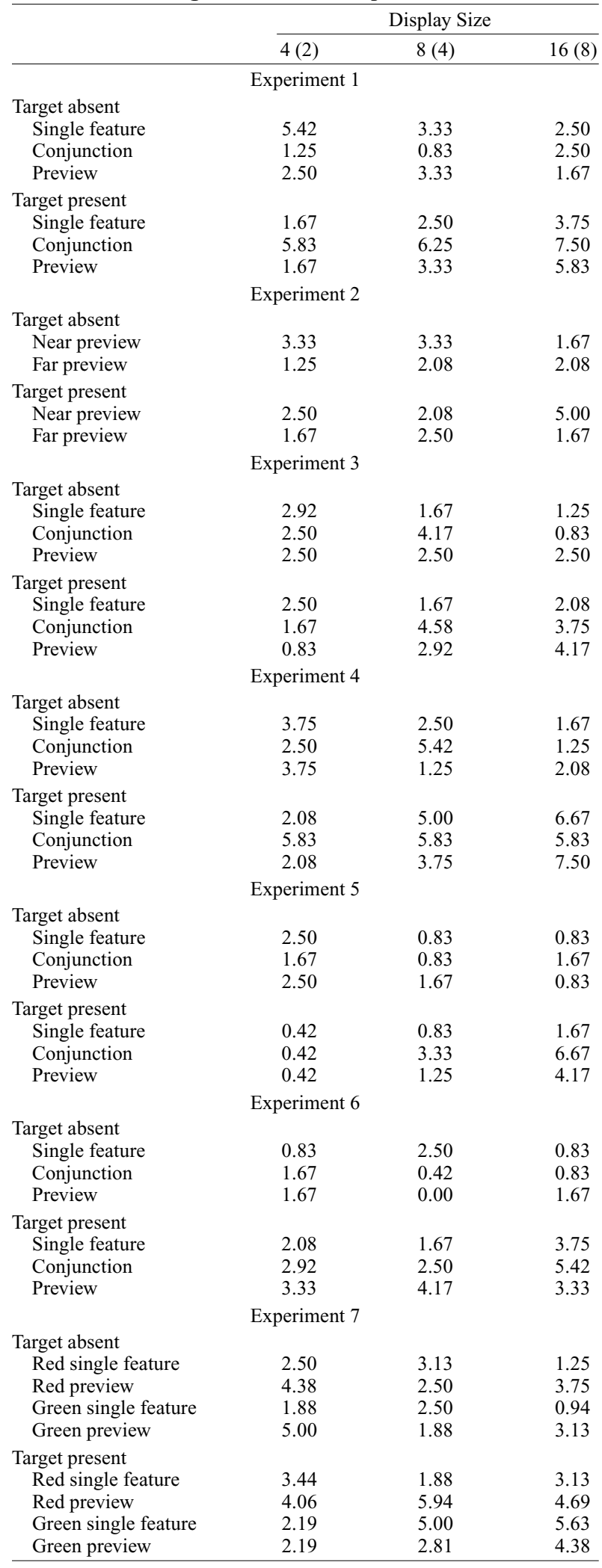

Note-The number of items in the single-feature baseline condition, given in parentheses, was half that in the conjunction baseline and preview conditions. trials $\left[F(1,11)=39.35, M S_{\mathrm{e}}=37,456, p<.001\right], \mathrm{RTs}$ increased with display size $\left[F(2,22)=61.55, M S_{\mathrm{e}}=\right.$ $26,856, p<.001]$ and RTs were shorter in the preview condition than in the conjunction baseline $[F(1,11)=$ $\left.29.38, M S_{\mathrm{e}}=11,811, p<.001\right]$. There was also a significant display size $\times$ condition interaction $[F(2,22)=$ $\left.22.22, M S_{\mathrm{e}}=7,610, p<.001\right]$. Search was less efficient in the conjunction baseline than in the preview condition. As expected, RTs also increased more with display size on absent trials than on present trials $[F(2,22)=$ $\left.43.06, M S_{\mathrm{e}}=6,837, p<.001\right]$. No other interactions approached significance.

Errors. There were more errors on present than on absent trials $\left[F(1,11)=6.46, M S_{\mathrm{e}}=52.02, p<.05\right]$, and there was a greater overall difference in error rates in the conjunction baseline and preview condition on absent trials $\left[F(1,11)=10.78, M S_{\mathrm{e}}=12.63, p<.01\right]$. No other main effects or interactions reached significance.

\section{Discussion}

Experiment 1 assessed the effect of abruptly appearing irrelevant stimuli (red disks) during the period when the old green distractors were being previewed prior to the onset of the new (blue) stimuli. Despite the appearance of abrupt onsets, search efficiency in the preview condition (as defined by search slopes) did not differ from that in the single-feature baseline (although RTs were longer overall). Also, search efficiency in the preview condition was more efficient (and shorter overall) than in the conjunction baseline. Thus observers remained able to successfully exclude old green distractors from search (albeit at an overall cost to average RT). The end result was a net increase in the effectiveness of real-time search performance.

This result contrasts with findings from previous studies in which the members of the initial preview changed their shape when the new items were added (Watson \& Humphreys, 2002). These results suggest that the extent to which change is disruptive depends upon whether it affects the old items in preview search. For example, according to Watson and Humphreys (1997), participants can intentionally suppress old items by setting up an inhibitory template when the old items appear (see also Humphreys, Watson, \& Jolicœur, 2002). This template may be reset by changes to the old items, but not necessarily by additional, transient changes produced by the irrelevant new stimuli, as here.

The irrelevant new onsets may not have been effective here for several reasons. One possibility is that the new red disks may have captured attention but were (on average) too dissimilar to the old distractors to disrupt search of those items. Another is that the red distractors fell too far from the old distractors to reset inhibition at old locations. A third is that $200 \mathrm{msec}$ may have been sufficiently long to enable the irrelevant red disks to be segmented in time from the second set of search stimuli, so the new search stimuli could still be attended efficiently (cf. Yantis \& Gibson, 1994). Note, however, that in prior studies, any alterations were made $250 \mathrm{msec}$ before the 
new items, and disruptive effects have been apparent (e.g., Watson \& Humphreys, 1997, Experiment 6). Hence, we think it unlikely that the timing of the change, before the new items, was critical here.

In Experiment 2, we tested whether the new onsets were not disruptive in Experiment 1 because they fell too far from the old distractors. In this case, the red disks either fell near to or far from the old distractors.

\section{EXPERIMENT 2 Effect of Proximity on Disruption}

\section{Method}

Participants. There were 12 participants ( 6 males, 6 females), aged 19-25 years $(M=21.1)$. All were undergraduate students at the University of Birmingham with self-reported normal or correctedto-normal visual acuity, and they participated for monetary payment.

Stimuli and Apparatus. The stimuli and apparatus were identical to those of Experiment 2, except for the following. There were two preview conditions. The near preview condition was identical to the preview condition of Experiment 1, except that a red disk was positioned either immediately above, below, left of, or right of each green $\mathrm{H}$ distractor. Thus, each green $\mathrm{H}$ distractor was paired with a red disk that fell $12 \mathrm{~mm}\left(1.15^{\circ}\right)$ away from it (center-to-center). In the far preview condition, the red disks were positioned randomly with the constraint that a red disk could not fall into any of the eight cells immediately surrounding a green $\mathrm{H}$ distractor. The minimum distance of a red disk from a green $\mathrm{H}$ distractor was $24 \mathrm{~mm}\left(2.29^{\circ}\right)$ center-to-center. The two standard search baselines were not presented because any differential effect of abrupt change proximity would be detectable by comparing across preview conditions.

\section{Results}

Figure 2 shows the RTs as a function of target presence, display size, and condition. Search slopes and percentage errors are displayed in Tables 1 and 2 .

Reaction times. The near condition was compared with the far condition, using a two-way within-subjects analysis of variance. Target-present trials were faster than target-absent trials $\left[F(1,11)=46.56, M S_{\mathrm{e}}=34,065\right.$, $p<.001]$, RTs increased with display size $[F(2,22)=$ 107.64, $\left.M S_{\mathrm{e}}=21,624, p<.001\right]$, and RTs increased more with display size on absent than on present trials $\left[F(2,22)=51.18, M S_{\mathrm{e}}=10,762, p<.001\right]$. No other main effects or interactions proved significant.

Errors. There were no significant effects.

\section{Discussion}

In Experiment 2, we examined further the effect of irrelevant abrupt onsets (red disks) appearing in the visual field on the preview benefit. In contrast to Experiment 1, these changes took place at locations that were either near to or far away from the old items (green H distractors). It is possible that the preview benefit would only be disrupted by irrelevant changes when they occur near to old (inhibited) stimuli. However, the results were not consistent with this proposal. There was no significant effect of the proximity of the irrelevant changes, and, for both near and far red disks, search efficiency was similar to that found in Experiment 1 (see Table 1 for the slopes of the search functions).

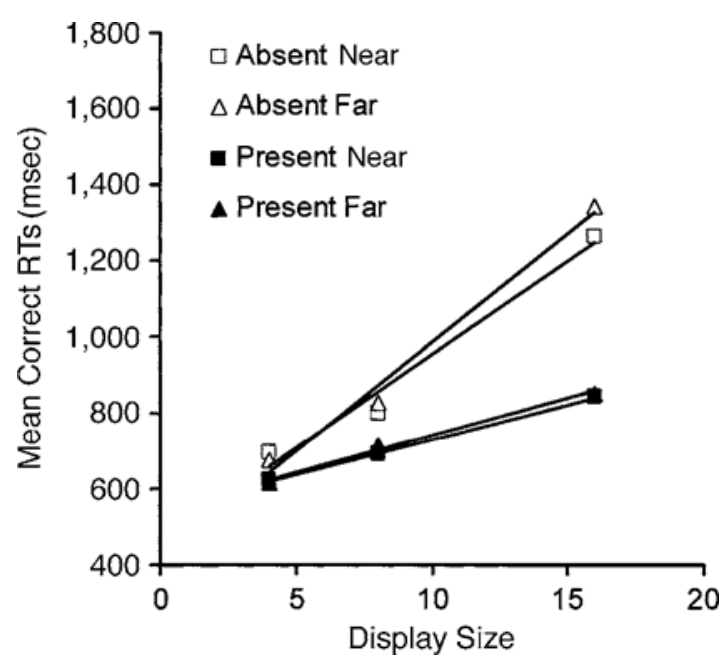

Figure 2. Mean correct response times (RTs) for Experiment 2 as a function of target presence, irrelevant distractor proximity, and display size.

In Experiment 3, we evaluated the possibility that the irrelevant new stimuli might draw attention back to the old green distractors if they group together. Once attended, the old green $\mathrm{H}$ distractors should then interfere with search for the blue $\mathrm{H}$ target, making performance approximate to the conjunction baseline. To facilitate grouping, the irrelevant stimuli were green.

\section{EXPERIMENT 3 \\ Green Irrelevant Onsets Appear Just Before the Search Display}

Experiment 3 replicated Experiment 1, but the irrelevant distractors were green disks (rather than red) thus sharing color with the old (to-be-ignored) green $\mathrm{H}$ stimuli. If old stimuli can compete for selection by grouping with new stimuli on the basis of color, we should expect the preview benefit to be disrupted when irrelevant new items have the same color as the old ignored stimuli.

\section{Method}

\section{Participants}

There were 12 participants ( 11 males, 1 female), aged 19-28 years $(M=20.8)$. All were undergraduate students at the University of Birmingham with self-reported normal or corrected-to-normal visual acuity, and they participated for monetary payment.

\section{Stimuli and Apparatus}

The stimuli and apparatus were identical to those of Experiment 1 , except that the irrelevant distractors were green disks rather than red disks. Thus in the preview condition, green $\mathrm{H}$ distractors were presented for $750 \mathrm{msec}$, after which green disks were added for $200 \mathrm{msec}$, followed by the remaining blue items (which contained the blue $\mathrm{H}$ target, when present).

\section{Design and Procedure}

The design and procedure were identical to those of Experiment 1. 


\section{Results \\ Single-Feature Versus Preview}

Figure 3 shows the RTs as a function of target presence, condition, and display size. Search slopes and percentage errors are shown in Tables 1 and 2 .

Reaction times. All three main effects proved significant; RTs were shorter on present trials than on absent trials $\left[F(1,11)=97.73, M S_{\mathrm{e}}=10,211, p<.001\right]$, increased with display size $\left[F(2,22)=122.46, M S_{\mathrm{e}}=\right.$ $7,257, p<.001]$, and were shorter overall in the singlefeature condition $\left[F(1,11)=17.34, M S_{\mathrm{e}}=22,146, p<\right.$ $.01]$. All the two-way interactions were also significant: target $\times$ display size $\left[F(2,22)=36.35, M S_{\mathrm{e}}=3,934\right.$, $p<.001]$, target $\times$ condition $\left[F(1,11)=7.73, M S_{\mathrm{e}}=\right.$ $25.07, p<.05]$, and condition $\times$ display size $[F(2,22)=$ $\left.14.65, M S_{\mathrm{e}}=2,359, p=.001\right]$. RTs were affected more by display size on absent trials than on present trials, and

\section{(A) Absent}

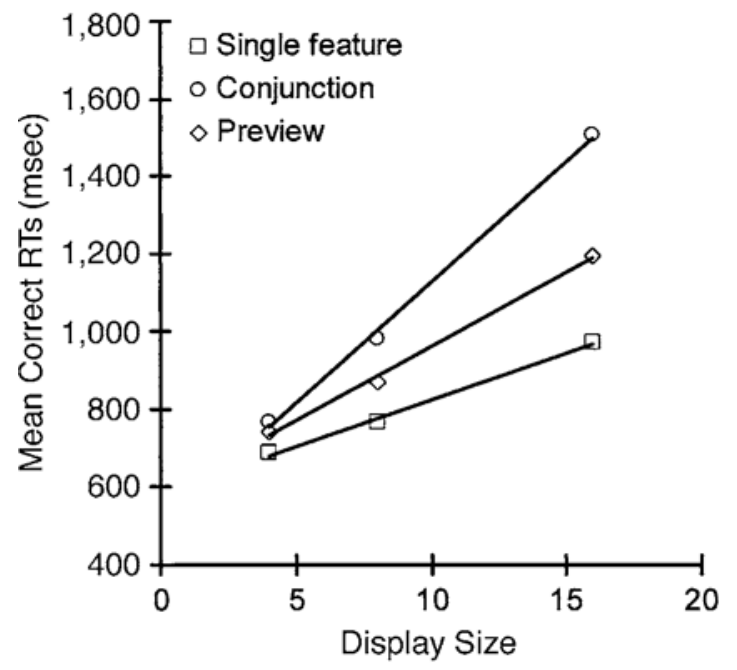

(B) Present

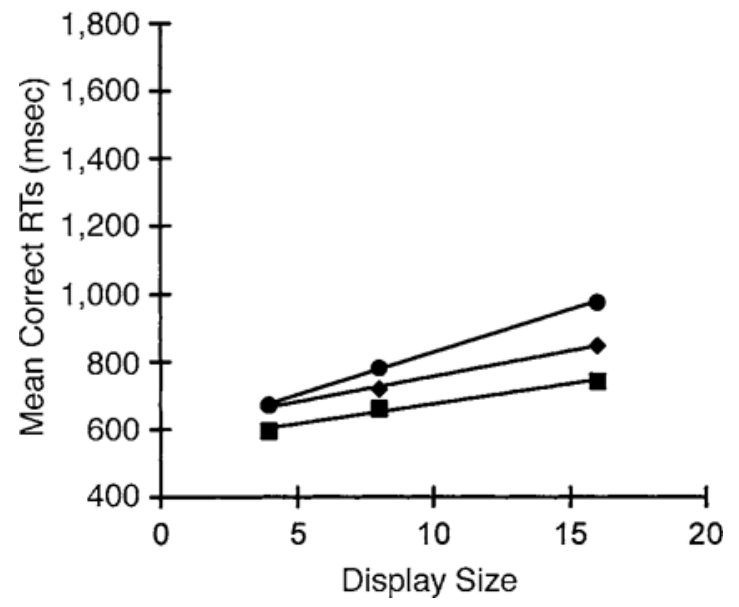

Figure 3. Mean correct response times (RTs) for Experiment 3 as a function of target presence, display size, and condition. there was a greater difference between absent and present RTs in the preview condition than in the single-feature baseline. Of most interest, RTs increased more overall with display size in the preview condition than in the singlefeature baseline. However, this was mostly due to a difference in absent trial search slopes as shown by a significant three-way interaction $\left[F(2,22)=4.05, M S_{\mathrm{e}}=\right.$ $3,498, p<.05]$. Indeed, when present trials were considered alone, the condition $\times$ display size interaction did not approach significance $\left[F(2,22)=2.24, M S_{\mathrm{e}}=\right.$ $1,638, p=.13]$.

Errors. There were no significant main effects or their interaction.

\section{Conjunction Versus Preview}

Reaction times. All three main effects were significant; RTs were shorter on present trials than on absent trials $\left[F(1,11)=237.02, M S_{\mathrm{e}}=8,214, p<.001\right]$, they increased with display size $\left[F(2,22)=390.64, M S_{\mathrm{e}}=\right.$ $5,676, p<.001]$, and they were shorter in the preview condition than in the conjunction baseline $[F(1,11)=$ $\left.37.18, M S_{\mathrm{e}}=11,060, p<.01\right]$. All the two-way interactions were also significant: target $\times$ display size $[F(2,22)=$ $\left.126.59, M S_{\mathrm{e}}=3,230, p<.001\right]$, target $\times$ condition $\left[F(1,11)=12.33, M S_{\mathrm{e}}=5,362, p<.01\right]$, and condition $\times$ display size $\left[F(2,22)=40.56, M S_{\mathrm{e}}=3,248, p<\right.$ $.001]$. RTs increased more with display size on absent trials than on present trials, the difference between presentand absent-trial RTs was greater in the conjunction baseline than in the preview condition, and RTs increased more with display size in the conjunction baseline condition than in the preview condition. The three-way interaction was also significant $\left[F(2,22)=7.48, M S_{\mathrm{e}}=\right.$ 2,912, $p<.01]$. However, taking present trials alone, there remained a highly significant display size $\times$ condition interaction $\left[F(2,22)=15.76, M S_{\mathrm{e}}=1,549, p<\right.$ .001].

Errors. Errors increased with display size $[F(2,22)=$ $\left.3.77, M S_{\mathrm{e}}=8.89, p<.05\right]$, and errors increased more with display size on present trials than on absent trials $\left[F(2,22)=3.49, M S_{\mathrm{e}}=10.78, p<.05\right]$. No other main effects or their interaction reached significance.

\section{Discussion}

Experiment 3 replicated Experiment 1, except that green (instead of red) disks acted as the irrelevant onset stimuli and so shared their color with the old items. Despite this change, the results were essentially the same as those in Experiment 1. On present trials, the search slope was shallower in the preview condition than in the conjunction baseline and did not differ significantly from the search slope in the single-feature baseline. On absent trials, the preview search slope fell between the slopes of the two baselines, indicating that some old items might also have been checked. However, absent trial data can be difficult to interpret, because observers may use a number of different strategies to determine target absence (e.g., Chun \& Wolfe, 1996; Humphreys \& Müller, 
1993). At most, it seems that abrupt changes to irrelevant distractors did not affect the efficiency of preview search, though such changes may have made observers more cautious in responding absent.

These results bear some similarity to those presented by Watson and Humphreys (1997), Experiment 7. They presented a preview condition in which some new green $\mathrm{H}$ distractors were presented along with the new blue $\mathrm{A}$ stimuli. The results showed that as the ratio of new-toold green stimuli increased, RTs systematically increased. Watson and Humphreys (1997) argued that this showed that the marking of stationary items was based on inhibition applied to the locations of the old items rather than their features (but see Olivers \& Humphreys, 2003; also see Watson \& Humphreys, 1998, for a different result with moving stimuli). However, Watson and Humphreys (1997) used only one display size and inferred decreased search efficiency from a general overall increase in RTs. The present experiment likewise shows that the appearance of stimuli sharing features with previously presented old (to-be-ignored) stimuli does not cause those items to recompete for selection (at least for stationary stimuli). Moreover, here we presented multiple display sizes and assessed search efficiency on the basis of search slopes rather than overall RTs, reducing the possibility that any differences were due to other factors, such as differential arousal, which ought to combine additively with the display size (Posner \& Boies, 1971). We conclude that the abrupt appearance of irrelevant stimuli that share color or are identical with the old distractors (Watson \& Humphreys, 1997) does not cause the old stimuli to recompete for selection with the new items.

\section{EXPERIMENT 4 \\ Blue Irrelevant Onsets Appear Just Before the Search Display}

Experiments 1-3 demonstrated that the sudden onset of irrelevant distractors did not disrupt the preview benefit when the features of the distractors were completely irrelevant (Experiments 1 and 2) or matched the features of the preview stimuli (Experiment 3). In Experiment 4, we examined the effects of newly appearing irrelevant distractors that carried the color of the new, search stimuli. There is now good evidence that visual search can be affected by an anticipatory set adopted in favor of the features of expected targets. For example, distractors sharing a singleton feature disrupt search but primarily when participants are set to detect singleton targets (Bacon \& Egeth, 1997). Likewise, effects of an irrelevant onset can be reduced when participants are set to search for color, and vice versa (Folk et al., 1992; Folk et. al, 1994). Braithwaite and Humphreys (2003) have also applied this idea to preview search. They found that search for a target was disrupted by previews sharing the same feature value, but this disruption was reduced when participants could anticipate the target's features (e.g., its color). From this, they proposed that participants can adopt a positive anticipatory set toward expected target features, as well as an inhibitory set against the old stimuli. Now consider what may happen in preview search when irrelevant stimuli onset just before the search display and these irrelevant stimuli have expected target features. If there is an anticipatory set toward expected target features, the irrelevant stimuli may now capture attention, because their features will match the anticipated target features. This capture of attentional resources could then disrupt the ability to maintain inhibition of the old stimuli. The result is that selective search through the new stimuli would be disrupted, since inhibition of the old stimuli would have been weakened. Note, however, that any disruptive effect might also be attributed to the similarity between the irrelevant distractors and the new search items. To test for this, the irrelevant distractors appeared in the baseline conditions, as well as in preview search. Similarity between the irrelevant distractors and the new search stimuli ought to affect the single-feature baseline as much they affect the preview condition.

\section{Method \\ Participants \\ There were 12 participants ( 2 males, 10 females) aged $18-20$ years $(M=18.8)$. All were undergraduate students at the University of Warwick with self-reported normal or corrected-to-normal visual acuity, and they participated for credit as part of an introductory psychology course.}

\section{Stimuli and Apparatus}

The stimuli and apparatus were similar to those of Experiment 1, except that the irrelevant distractors were blue disks rather than red disks, and they were presented on a 17 -in. monitor driven by a $400-$ $\mathrm{MHz}$ Pentium-based computer. In the preview condition, green $\mathrm{H}$ distractors were presented for $750 \mathrm{msec}$, after which blue disks were added for $200 \mathrm{msec}$ followed by the remaining blue items (which contained the blue $\mathrm{H}$ target, when present). The blue disks also appeared $200 \mathrm{msec}$ before the search display in the single-feature and conjunction baseline conditions.

\section{Design and Procedure}

The design and procedure were identical to those of Experiment 1 .

\section{Results}

Figure 4 shows the RTs as a function of target presence, display size, and condition. Search slopes and percentage errors are displayed in Tables 1 and 2.

\section{Single-Feature Versus Preview}

Reaction times. All three main effects proved significant; RTs were shorter on present trials than on absent trials $\left[F(1,11)=97.96, M S_{\mathrm{e}}=21,406, p<.001\right]$, they increased with display size $\left[F(2,22)=109.13, M S_{\mathrm{e}}=\right.$ $19,986, p<.001]$, and they were shorter overall in the single-feature condition $\left[F(1,11)=45.88, M S_{\mathrm{e}}=30,748\right.$, $p<.001]$. All the two-way interactions were also significant: target $\times$ display size $\left[F(2,22)=36.67, M S_{\mathrm{e}}=6,568\right.$, $p<.001]$, target $\times$ condition $\left[F(1,11)=52.70, M S_{\mathrm{e}}=\right.$ 


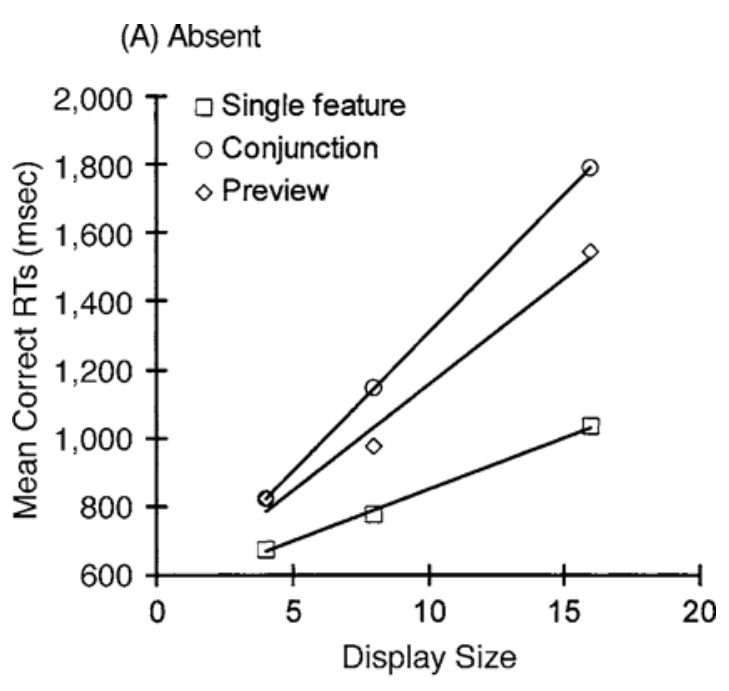

(B) Present

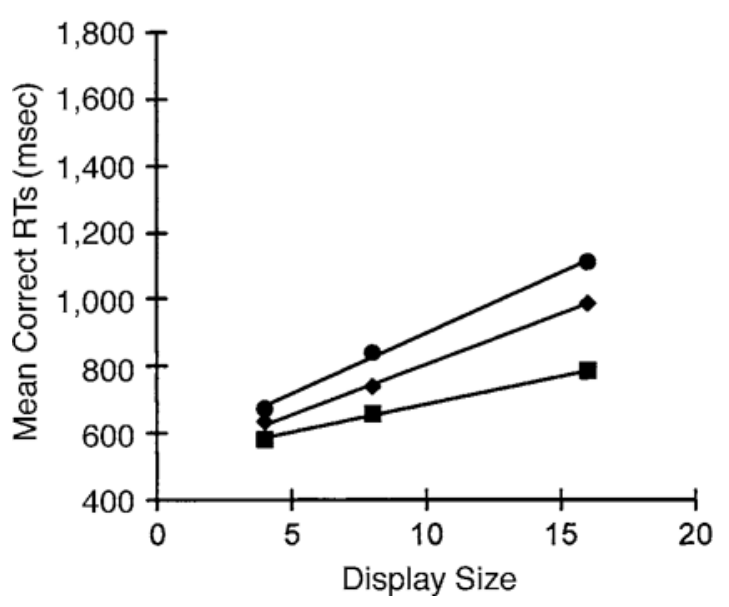

Figure 4. Mean correct response times (RTs) for Experiment 4 as a function of target presence, display size, and condition.

$5,211, p<.05]$, and condition $\times$ display size $[F(2,22)=$ $\left.27.25, M S_{\mathrm{e}}=8,451, p<.001\right]$. RTs increased more by display size on absent trials than on present trials, there was a greater overall difference between absent and present RTs in the preview condition compared with the baseline condition, and RTs increased more with display size in the preview condition than in the baseline condition. The three-way interaction was also significant $[F(2,22)=$ $\left.9.06, M S_{\mathrm{e}}=4,489, p<.01\right]$. The slope difference between the single-feature and preview condition was greatest on absent trials. However, a significant slope difference remained on present trials alone $[F(2,22)=$ $\left.14.76, M S_{\mathrm{e}}=2,627, p<.001\right]$.

Errors. Errors tended to be greater on present trials $\left[F(1,11)=4.67, M S_{\mathrm{e}}=31.23, p=.054\right]$ and increased more with display size on present trials than on absent trials $\left[F(2,22)=9.63, M S_{\mathrm{e}}=14.95, p<.01\right]$. No other main effects or their interaction were significant.

\section{Conjunction Versus Preview}

Reaction times. All three main effects were significant; RTs were shorter on present trials $[F(1,22)=$ $\left.191.98, M S_{\mathrm{e}}=23,421, p<.001\right]$, in the preview condition $\left[F(1,11)=7.28, M S_{\mathrm{e}}=63,672, p<.05\right]$, and they increased with display size $\left[F(2,22)=216.44, M S_{\mathrm{e}}=\right.$ $22,583, p<.001]$. RTs increased more with display size on absent trials than on present trials $[F(1,11)=80.67$, $\left.M S_{\mathrm{e}}=8,338, p<.01\right]$, and they increased more with display size in the conjunction condition than in the preview condition $\left[F(2,22)=3.83, M S_{\mathrm{e}}=22,168, p<.05\right]$. No other interactions were significant.

Errors. There were more errors on present trials than on absent trials $\left[F(1,11)=10.91, M S_{\mathrm{e}}=19.49, p<\right.$ $.01]$, and errors increased more on present trials with display size than on absent trials $\left[F(2,22)=3.60, M S_{\mathrm{e}}=\right.$ $16.84, p<.05]$. No other main effects or their interaction was significant.

\section{Discussion}

In contrast to Experiments 1-3, the irrelevant disks now disrupted search efficiency, and this effect was selective to the preview condition. The disruptive effects cannot be attributed to the onsets themselves, and the effects cannot be attributed to the similarity between the features of the irrelevant items and the new search stimuli, since these factors should have affected the singlefeature baseline as much as they affected preview search. Instead, the data suggest that the irrelevant changes were disruptive because these stimuli shared features of the anticipated new targets (both were blue). This suggests that in addition to any inhibition applied to the old items, participants undertaking preview search can hold an anticipatory set for properties of the new items (see Braithwaite \& Humphreys, 2003). However, in the present case, features of the irrelevant new items match the anticipatory set, causing these items to capture attention. As a consequence, inhibition of the old items was reduced, and search efficiency in the preview condition was disrupted.

In the final three experiments (5-7), we used a different procedure. Instead of presenting the irrelevant stimuli after the old items had been in the field for some time, we displayed the irrelevant stimuli simultaneously with the old distractors. We then made a transient change to the irrelevant items $250 \mathrm{msec}$ before the appearance of the new search stimuli. This change was to blank the irrelevant items off, re-presenting them when the new items appeared. As we have noted in the introduction, efficient preview search may in part be contingent on the suppression of the old distractors, based on an inhibitory template generated when these items first appear (Humphreys, Watson, \& Jolicœur, 2002; Watson \& Humphreys, 1997). This inhibitory template may specify all the items in the old group, not just those that could compete for selection with the target. In this case, changes to irrelevant items may be disruptive, because they may make all the old items compete with the new stimuli in search. We 
tested this in Experiment 4, by presenting irrelevant red disks along with the old green distractors. In Experiment 5, we assessed the effects of grouping by using irrelevant green disks, which shared their color with the old distractors. Experiment 7 provided a within-subjects comparison of the latter two conditions. Here, we asked whether performance can be disrupted by irrelevant change to the initial inhibitory template.

\section{EXPERIMENT 5}

Irrelevant Red Disks Disappear and Reappear

\section{Method}

\section{Participants}

There were 12 participants ( 7 males, 5 females) aged $18-26$ years $(M=21.1)$. All were undergraduate students at the University of Birmingham with self-reported normal or corrected-to-normal visual acuity, and they participated for monetary payment.

\section{Stimuli and Apparatus}

The stimuli and apparatus were identical to those of Experiment 1 , except for the following. In the preview condition, the red disks appeared at the same time as the green $\mathrm{H}$ distractors. After $750 \mathrm{msec}$, the red disks disappeared, and $250 \mathrm{msec}$ later they reappeared (at the same locations) and at the same time the blue stimuli were added. In the single-feature and conjunction conditions, the search display (also containing the red disks) was presented immediately after the fixation cross.

\section{Results}

Figure 5 shows the RTs as a function of target presence, display size, and condition. Search slopes and percentage errors are displayed in Tables 1 and 2 .

\section{Single-Feature Versus Preview}

Reaction times. All three main effects proved significant; RTs were shorter on present trials than on absent trials $\left[F(1,11)=41.19, M S_{\mathrm{e}}=41,462, p<.001\right]$, they increased with display size $\left[F(2,22)=47.29, M S_{\mathrm{e}}=38,393\right.$, $p<.001]$ and they were shorter overall in the singlefeature condition $\left[F(1,11)=27.45, M S_{\mathrm{e}}=12,606, p<\right.$ $.001]$. All the two-way interactions were also significant: target $\times$ display size $\left[F(2,22)=20.02, M S_{\mathrm{e}}=16,431\right.$, $p<.001]$, target $\times$ condition $\left[F(1,11)=6.10, M S_{\mathrm{e}}=\right.$ $9,327, p<.05]$, and condition $\times$ display size $[F(2,22)=$ $\left.17.22, M S_{\mathrm{e}}=2,275, p<.001\right]$. RTs were affected more by display size on absent trials than on present trials, there was a greater difference between absent and present RTs in the preview condition than in the single-feature baseline, and RTs increased more with display size in the preview condition than in the single-feature baseline. However, the three-way interaction was also significant $\left[F(2,22)=5.51, M S_{\mathrm{e}}=3,034, p<.05\right]$. The difference in slope between the single-feature and preview condition was greatest on absent trials. Taking present trials alone revealed a borderline display size $\times$ condition interaction $\left[F(2,22)=3.41, M S_{\mathrm{e}}=1,523, p=.051\right]$.

Errors. There was a significant target $\times$ display size interaction $\left[F(2,22)=3.78, M S_{\mathrm{e}}=13.81, p<.05\right]$. Er-
(A) Absent

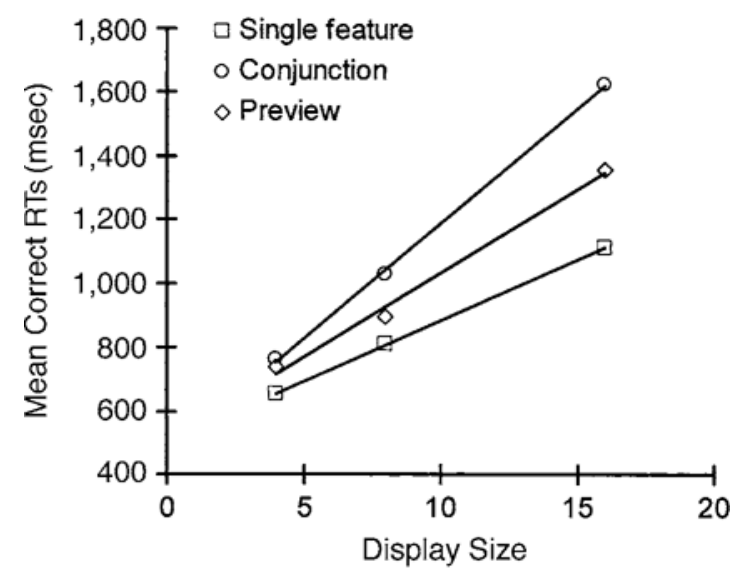

(B) Present

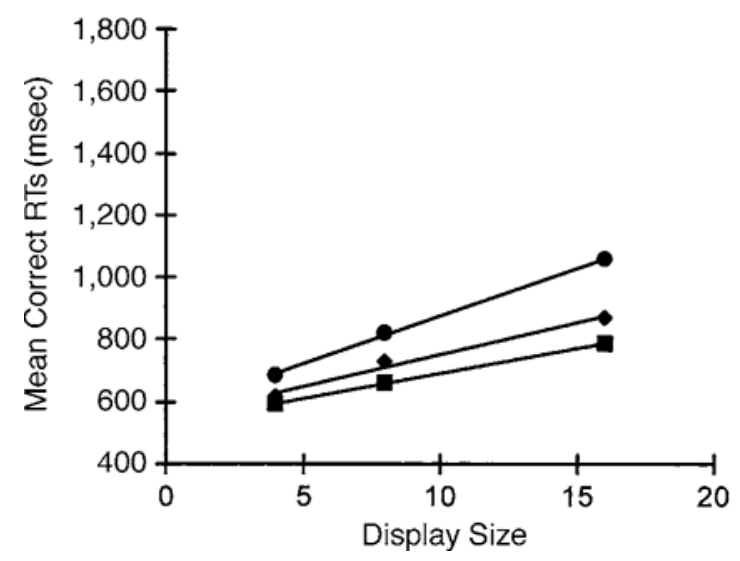

Figure 5. Mean correct response times (RTs) for Experiment 5 as a function of target presence, display size, and condition.

rors increased more with display size on present trials than on absent trials. No other main effects or their interaction approached significance.

\section{Conjunction Versus Preview}

Reaction times. All three main effects were significant; RTs were shorter on present trials than on absent trials $\left[F(1,11)=63.06, M S_{\mathrm{e}}=42,113, p<.001\right]$, they increased with display size $\left[F(2,22)=67.13, M S_{\mathrm{e}}=\right.$ $51,881, p<.001]$, and they were faster overall in the preview condition $\left[F(1,11)=23.26, M S_{\mathrm{e}}=25,960, p<\right.$ $.001]$. The target $\times$ display size $\left[F(2,22)=25.95, M S_{\mathrm{e}}=\right.$ $23,623, p<.001]$ and the display size $\times$ condition interaction were also significant $\left[F(2,22)=12.30, M S_{\mathrm{e}}=\right.$ $8,497, p<.001]$. RTs increased more with display size on absent trials than on present trials and increased more with display size in the conjunction baseline than in the preview condition. The three-way interaction was also significant $\left[F(2,22)=3.76, M S_{\mathrm{e}}=3,085, p<.05\right]$. The difference in the search slopes between the preview and the conjunction condition was larger on absent trials than 
on present trials. However, taking present trials alone, there remained a robust condition $\times$ display size interaction $\left[F(2,22)=6.88, M S_{\mathrm{e}}=3,603, p<.01\right]$.

Errors. There were more errors on present trials than on absent trials $\left[F(1,11)=4.82, M S_{\mathrm{e}}=10.40, p=.05\right]$, errors increased with display size $\left[F(2,22)=8.07, M S_{\mathrm{e}}=\right.$ $6.99, p<.01]$, and this increase was greater on present trials than on absent trials $\left[F(2,22)=8.58, M S_{\mathrm{e}}=11.92\right.$, $p<.01]$. There was also a trend for errors to increase more with display size in the conjunction condition than in the preview condition $\left[F(2,22)=2.89, M S_{\mathrm{e}}=4.5, p=\right.$ $.077]$. This shows that the finding of reduced search slope in the preview condition relative to the conjunction condition was not compromised by a speed-accuracy tradeoff.

\section{Discussion}

In Experiment 1, red disks were presented before the new blue items but after the old items had been in the field long enough to establish a preview effect. In contrast, in Experiment 5, red disks were displayed simultaneously with the old green distractors and were thus present when any initial template for visual marking may have been established. After $750 \mathrm{msec}$, the disks disappeared and then reappeared along with the new blue items. Search was substantially more efficient in the preview condition than in the conjunction baseline. However, there was a borderline interaction between the preview and the single-feature condition that, if reliable, would indicate that the preview benefit had been disrupted. In Experiment 6, we asked whether a stronger disruption results when the irrelevant items share their color with the old distractors so that they may both group initially on the basis of color.

\section{EXPERIMENT 6 \\ Irrelevant Green Disks Disappear and Reappear}

\section{Method}

\section{Participants}

There were 12 participants ( 3 males, 9 females), aged 18-21 years $(M=19.3)$. All were undergraduate students at the University of Birmingham with self-reported normal or corrected-to-normal visual acuity, and they participated for monetary payment.

\section{Stimuli and Apparatus}

The stimuli and apparatus were identical to those of Experiment 5 , except that the irrelevant distractors were green disks rather than red disks. That is, in the preview condition, the green $\mathrm{H}$ distractors and green disks were presented for $750 \mathrm{msec}$, after which the green disks disappeared for $250 \mathrm{msec}$ and then reappeared along with the blue stimuli (which would contain the blue $\mathrm{H}$ target when present).

Design and Procedure

The design and procedure were identical to those of Experiment 5 .

\section{Results}

\section{Single-Feature Versus Preview}

Figure 6 shows the RTs as a function of target presence, condition, and display size. Search slopes and percentage errors are shown in Tables 1 and 2.
Reaction times. All three main effects proved significant; RTs were shorter on present trials than on absent trials $\left[F(1,11)=91.28, M S_{\mathrm{e}}=13,142, p<.001\right]$, they increased with display size $\left[F(2,22)=91.32, M S_{\mathrm{e}}=13,607\right.$, $p<.001]$, and they were shorter overall in the singlefeature condition $\left[F(1,11)=12.95, M S_{\mathrm{e}}=22,936, p<\right.$ $.01]$. All the two-way interactions were also significant: target $\times$ display size $\left[F(2,22)=23.33, M S_{\mathrm{e}}=9,389\right.$, $p<.001]$, target $\times$ condition $\left[F(1,11)=15.13, M S_{\mathrm{e}}=\right.$ $3,929, p<.01]$, and condition $\times$ display size $[F(2,22)=$ 9.04, $\left.M S_{\mathrm{e}}=3,728, p=.001\right]$. RTs were affected more by display size on absent trials than on present trials, and there was a greater difference between absent and present RTs in the preview condition than in the single-feature baseline. Of most importance, RTs increased more with display size in the preview condition than in the singlefeature baseline, signaling that search was less efficient in the preview condition than in the single-feature baseline. The three-way interaction did not approach significance, $(F<1)$.

Errors. The main effect of target approached significance $\left[F(1,11)=4.64, M S_{\mathrm{e}}=25.32, p=.054\right]$ with a
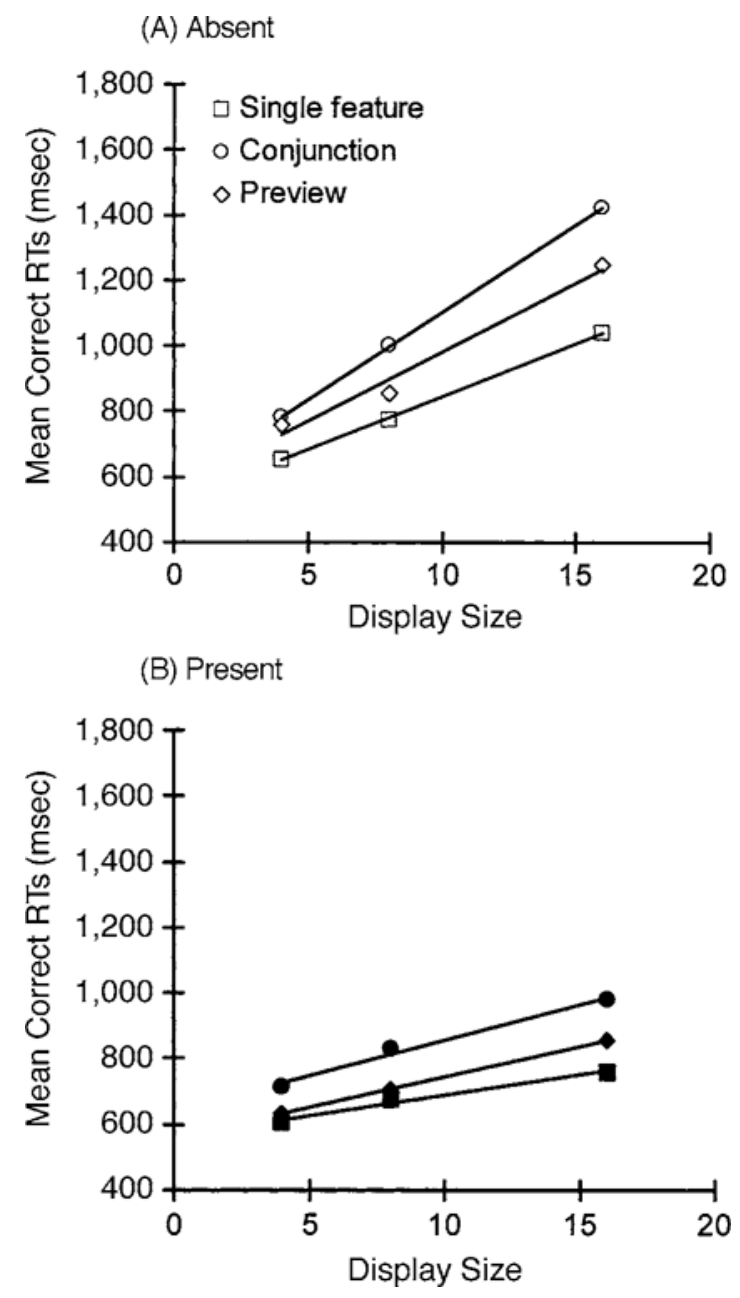

Figure 6. Mean correct response times (RTs) for Experiment 6 as a function of target presence, display size, and condition. 
trend for more errors on present trials than on absent trials. No other main effects or their interaction reached significance.

\section{Conjunction Versus Preview}

Reaction times. All three main effects were significant; RTs were faster on present trials than on absent trials $\left[F(1,11)=136.61, M S_{\mathrm{e}}=13,353, p<.001\right]$, RTs increased with display size $\left[F(2,22)=146.60, M S_{\mathrm{e}}=\right.$ $13,991, p<.001]$, and RTs were faster in the preview condition than in the conjunction baseline $[F(1,11)=$ $\left.13.89, M S_{\mathrm{e}}=32,369, p<.01\right]$. RTs also increased more with display size on absent trials than on present trials $\left[F(2,22)=28.86, M S_{\mathrm{e}}=12,040, p<.001\right]$ and increased more with display size in the conjunction baseline than in the preview condition $\left[F(2,22)=4.33, M S_{\mathrm{e}}=7,351\right.$, $p<.05]$. No other interactions approached significance.

Errors. There were more errors on present trials than on absent trials $\left[F(1,11)=9.44, M S_{\mathrm{e}}=25.17, p<\right.$ $.05]$. No other main effects or their interaction reached significance.

\section{Discussion}

In the present experiment, green $\mathrm{H}$ distractors were presented along with green disk distractors, and after $750 \mathrm{msec}$, the green disks disappeared and then reappeared $250 \mathrm{msec}$ later along with the blue stimuli. Search efficiency in the preview condition now clearly fell between that of the single-feature and conjunction baselines on both present and absent trials. Given that the disruption here appeared greater than that observed in Experiment 5 (i.e., it was not based on a borderline probability), it might be crucial that the old disks initially group with the old distractors for disruption to occur. However, to test this possible difference we performed an additional experiment that directly assessed any differences in preview disruption as a function of old itemdisk grouping using a within-subjects design.

\section{EXPERIMENT 7 Within-Subjects Comparison of Red Versus Green Disk Changes}

Method
Participants
There were 16 participants (all female), aged 18-20 years ( $M=$
18.8). All were undergraduate students at the University of War-
wick with self-reported normal or corrected-to-normal visual acu-
ity and they participated for credit as part of an introductory psy-
chology course.
Stimuli and Apparatus
The apparatus was identical to that of Experiment 4 , and stimuli
were based on those of Experiments 5 and 6 . Each participant com-
pleted four conditions: the single-feature baseline and preview con-
ditions of Experiment 5 (red disks) and the single-feature baseline
and preview conditions of Experiment 6 (green disks). We did not
include the conjunction baseline, to maintain a comparable number
of trials to the other experiments reported here, and because of most

interest was whether or not the irrelevant changes were disruptive in the preview conditions relative to the single-feature baselines (which had produced a marginal interaction in Experiment 5 and a substantial interaction in Experiment 6).

\section{Design and Procedure}

Each participant completed one block of trials for each condition, with order counterbalanced.

\section{Results}

Figure 7 shows the RTs as a function of target presence, display size, and condition. Search slopes and percentage errors are displayed in Tables 1 and 2. Disruption to marking was assessed by comparing each preview condition with the appropriate single-feature baseline. We also compared the two preview and two single-feature conditions directly.

\section{Red Preview Versus Red Single-Feature Baseline}

Reaction times. All three main effects proved significant; RTs were faster on present trials than on absent trials $\left[F(1,15)=71.83, M S_{\mathrm{e}}=18,362, p<.001\right]$, they increased with display size $\left[F(2,30)=126.71, M S_{\mathrm{e}}=\right.$ $13,920, p<.001]$, and they were shorter overall in the single-feature condition $\left[F(1,15)=33.86, M S_{\mathrm{e}}=\right.$ $22,409, p<.001]$. All the two-way interactions were also significant: target $\times$ display size $[F(2,30)=40.10$, $\left.M S_{\mathrm{e}}=5,738, p<.001\right]$, target $\times$ condition $[F(1,15)=$ $\left.6.12, M S_{\mathrm{e}}=9,294, p<.05\right]$ and condition $\times$ display size $\left[F(2,30)=19.65, M S_{\mathrm{e}}=9,570, p<.001\right]$. RTs increased more by display size on absent trials than on present trials, there was a greater overall difference between absent and present RTs in the preview condition compared with the baseline, and RTs increased more with display size in the preview condition than in the baseline. The three-way interaction was also significant $\left[F(2,30)=10.82, M S_{\mathrm{e}}=3,772, p<.001\right]$. The slope difference between the single-feature and preview condition was greatest on absent trials. However, there was a highly significant slope difference even on present trials alone $\left[F(2,30)=7.26, M S_{\mathrm{e}}=3,792, p<.01\right]$.

Errors. Error rates were higher overall in the preview condition than in the single-feature baseline $[F(1,15)=$ $\left.8.73, M S_{\mathrm{e}}=15.28, p=.01\right]$, and they increased most with display size on present trials in the preview condition, as shown by a significant three-way interaction $\left[F(2,30)=3.80, M S_{\mathrm{e}}=11.74, p<.05\right]$. No other main effects or their interaction were significant.

\section{Green Preview Versus Green Single-Feature Baseline}

Reaction times. The pattern of data and significance levels were essentially the same as for the red single-feature versus red preview condition: All three main effects were significant; RTs were shorter on present trials $\left[F(1,15)=84.11, M S_{\mathrm{e}}=15,734, p<.001\right]$, and in the single-feature baseline $\left[F(1,15)=37.66, M S_{\mathrm{e}}=21,152\right.$, $p<.001]$ and increased with display size $[F(2,30)=$ 


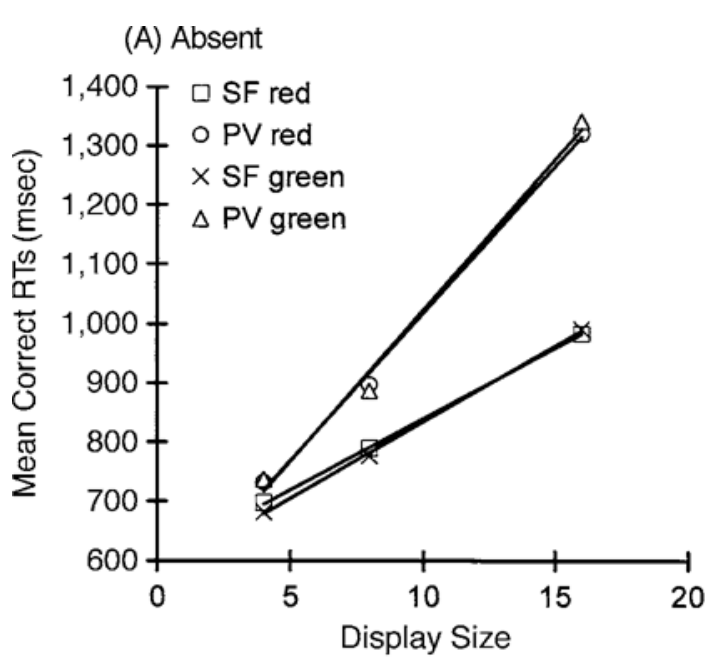

(B) Present

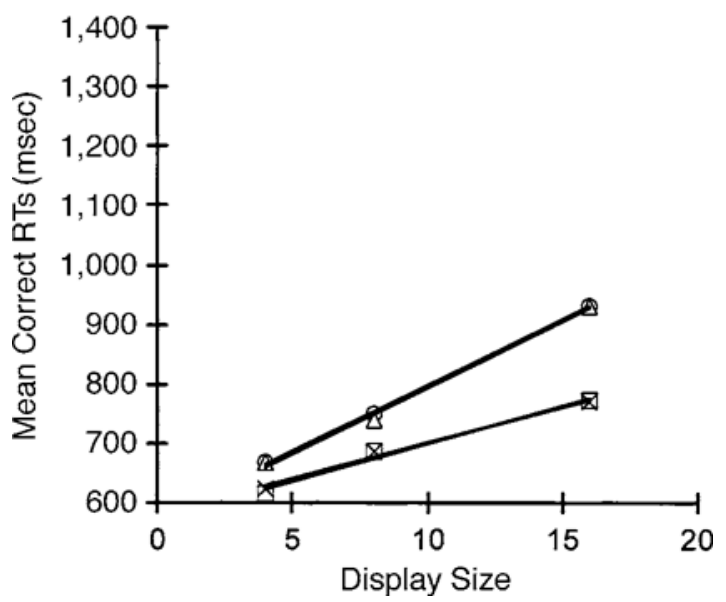

Figure 7. Mean correct response times (RTs) for Experiment 7 as a function of target presence, display size, and condition. SF, single-feature baseline; PV, preview.

$\left.124.85, M S_{\mathrm{e}}=14,887, p<0.001\right]$. All the two-way interactions were also significant; target $\times$ display size $\left[F(2,30)=32.43, M S_{\mathrm{e}}=8,603, p<.001\right]$, target $\times$ condition $\left[F(1,15)=16.55, M S_{\mathrm{e}}=5,350, p=.01\right]$, and condition $\times$ display size $\left[F(2,30)=22.50, M S_{\mathrm{e}}=8,735\right.$, $p<.001]$, as was the three-way interaction $[F(2,30)=$ $\left.5.89, M S_{\mathrm{e}}=5,963, p<.01\right]$. Again, search slopes were shallower in the baseline than in the preview condition, and this was greatest on absent trials, although the slope difference was still significant on present trials alone $\left[F(2,30)=8.00, M S_{\mathrm{e}}=4136, p<.01\right]$.

Errors. There were more errors on present trials than on absent trials $\left[F(1,15)=6.70, M S_{\mathrm{e}}=9.41, p<.05\right]$, but this effect tended to be evident only in the single-feature condition $\left[F(1,15)=4.29, M S_{\mathrm{e}}=20.52, p=.056\right]$. Errors also increased more with display size on present trials than on absent trials $\left[F(2,30)=5.70, M S_{\mathrm{e}}=13.19\right.$, $p<.01]$. No other main effects or their interactions reached significance.
Red Single Feature Versus Green Single Feature

Reaction times. RTs were faster on present trials than on absent trials $\left[F(1,15)=51.76, M S_{\mathrm{e}}=15,006\right.$, $p<.001]$, increased with display size $[F(2,30)=$ $\left.108.98, M S_{\mathrm{e}}=7,641, p<.001\right]$ and this was greatest on absent trials $\left[F(2,30)=17.23, M S_{\mathrm{e}}=5,587, p<.001\right]$. However, no other main effects or their interaction were significant.

Errors. There were more errors on absent trials than on present trials $\left[F(1,15)=5.46, M S_{\mathrm{e}}=20.06, p<.05\right]$, and this was greater in the green single feature than in the red single feature condition $\left[F(1,15)=5.09, M S_{\mathrm{e}}=\right.$ 9.23, $p<.05]$. However, no other main effects or their interactions were significant.

\section{Red Preview Versus Green Preview}

Reaction times. Overall RTs were faster on present trials $\left[F(1,15)=90.46, M S_{\mathrm{e}}=22,210, p<.001\right]$, and search slopes were shallower $\left[F(2,30)=43.99, M S_{\mathrm{e}}=\right.$ $11,079, p<.001]$, than on absent trials, and RTs increased with display size $\left[F(2,30)=109.06, M S_{\mathrm{e}}=\right.$ $29,089, p<.001]$. However, no other main effects or their interactions reached significance.

Errors. Errors increased more with display size on present trials than on absent trials $\left[F(2,30)=5.53, M S_{\mathrm{e}}=\right.$ $10.76 p<.001]$, and there was also a marginal target $\times$ condition interaction $\left[F(1,15)=4.14, M S_{\mathrm{e}}=7.07, p=\right.$ $.06]$. No other main effects or their interaction reached significance.

\section{Discussion}

In terms of search rates, there was no difference in performance between the two baselines. This indicates that the color of the irrelevant disks (red or green) did not differentially impact the search for a blue $\mathrm{H}$ target among blue A distractors. Similarly, there was no difference in search rate between the two preview conditions. However, of most relevance was the finding of a highly significant difference in search rates between both of the preview conditions and their corresponding baselines. This shows that the removal and reappearance of irrelevant disks that were initially presented at the same time as the old items disrupted the preview benefit. Moreover, the disruption was not contingent on them sharing features with the old to-be-ignored stimuli.

\section{GENERAL DISCUSSION}

\section{Summary of Findings}

In seven experiments, we investigated the effect of irrelevant changes occurring in the visual field on the preview benefit. Experiments 1-3 showed that the appearance of irrelevant abrupt-onset distractors during the preview period just before the new items were added had little impact on the preview benefit even if they shared features (color) with the old items. However, if they shared color with the new items (Experiment 4), the preview benefit was reduced but not eliminated. 
In Experiments 5-7, irrelevant disks were presented at the same time as were the old items; they then disappeared and reappeared with the new items. In this situation, changes to the irrelevant items disrupted but did not abolish the preview benefit, irrespective of whether or not they shared features with any other items in the display.

\section{Disruption by Irrelevant Onsets}

One aim of this study was to determine whether irrelevant changes occurring in the visual field would disrupt the preview benefit. Experiments 1-3 showed that if the items did not share color with the new stimuli, they did not. This was true even if they shared color with the old items and could therefore group with them. In contrast, when the irrelevant onsets shared color with the new items, they disrupted but did not abolish the preview benefit (Experiment 4). Thus, irrelevant onsets do not appear to draw sufficient attentional resources as to impact the maintenance of the marking template (cf. Rensink, 2000), unless they share the color of the new items. In that case, they act like a load task that requires attentional resources (e.g., digit shadowing) presented during the preview period, which is sufficient to disrupt (but not eliminate) the preview benefit (e.g., Humphreys, Watson, \& Jolicœur, 2002; Watson \& Humphreys, 1997).

Humphreys, Watson, and Jolicœur (2002) demonstrated that the process of visual marking can be fractionated into an early "setup" component in which the intention to inhibit old items is generated and a template is formed, and a later "maintenance" component in which the inhibition of the old items is maintained once set up. The setup component was disrupted by both auditory and visual secondary load tasks consistent with it requiring general modality-independent resources. In contrast, the maintenance component was disrupted only by the visual load task consistent with the maintenance of visual marking requiring modality-specific resources. It remains possible that the preview benefit might be disrupted by abrupt onsets that do not share the target features occurring in the more fragile setup period that may be more sensitive to resource fluctuations than the maintenance process.

\section{Nature of the Template}

Previously we (Watson, 2001; Watson \& Humphreys, 1997, 1998) have speculated that the marking template codes the locations of old "to-be-ignored" stimuli and is set up as a result of the adoption of an inhibitory goal state during the preview period. The locations of individual items might be coded independently, or individual items might be coded as parts or features of a single-object representation (Watson \& Humphreys, 1997). The present data support the latter possibility. We found that, when irrelevant items were likely to be coded into the representation of the preview (Experiments 5-7), changes to them did disrupt search. This is consistent with these changes resetting the representation of the preview, so that the old items competed with the new search displays.
The findings suggest that, even when old items differ in color and shape, there is some grouping based on their shared onset (see also Jiang, Chun, \& Marks, 2002, and Humphreys, Riddoch, Nys, \& Heinke, 2002, for neuropsychological evidence for grouping by common onset). Other studies, however, indicate that there can be grouping by featural properties (e.g., color). Braithwaite, Humphreys, and Hulleman (2004) used a probe detection technique to examine the allocation of attention to old and new stimuli in preview search. As in other studies, they found that probes on old items were more difficult to detect than probes on new stimuli (see Humphreys, Jung-Stallmann, \& Olivers, 2004; Olivers \& Humphreys, 2002; Watson \& Humphreys, 2000). In addition, detection was particularly difficult if the probe fell on an old item that was in a majority color in the preview. Braithwaite et al. proposed that items in the preview grouped by color as well as by common onset and that items in the larger group were subject to greater inhibition than were items in the smaller group-a process that might be mediated by "spreading suppression" between the old distractors (see Duncan \& Humphreys, 1989). Nevertheless, even weak grouping by common onset may be sufficient to link items in the preview to the irrelevant distractors in the present study, so that changes to the irrelevant items make the preview items compete with the search display again for selection. This resetting of the old items may come about because the display changes feedback and reset the inhibitory template applied to the preview (cf. Rensink, 2000).

\section{Feature-Based Inhibition and Evidence for an Anticipatory Set}

Watson and Humphreys $(1997,1998)$ originally proposed that old stationary items were subject to inhibition applied to their locations. However, as we have noted, recent work suggests that feature-based inhibition can operate even with stationary stimuli. For example, there is a reduced preview benefit when the old and new items share color (Gibson \& Jiang, 2001). Similarly, Olivers and Humphreys (2002) found evidence of feature-based inhibition when a subsequently presented target shared its color with items from a previously ignored preview display (a color "carryover" effect).

The present results show that, in addition to any inhibitory filtering of old distractors, performance is affected by a positive, anticipatory set for new items, based upon the expected features of targets (see also Braithwaite \& Humphreys, 2003). In Experiments 1-4, we found that presentation of irrelevant disks just before the new search display disrupted the preview benefit only when the irrelevant stimuli shared their color with the new items. In contrast, if the irrelevant distractors were the same color as the old items, or if they did not share color with any of the search stimuli, performance was unaffected. Thus, abrupt irrelevant onsets were effective only if they shared features with the anticipatory set for the target. We suggest that, under these conditions, the 
irrelevant stimuli captured attention, drawing resources away from the new search items and away from the inhibitory set applied to the old items. The net result was that preview search was selectively disrupted.

However, the present data also suggest that featurebased inhibition does not operate in isolation from other effects, because feature values did not modulate the detrimental effects of changing irrelevant items when those items onset with the preview. One view of these results is that inhibition takes place automatically on both the features and the locations occupied by a first group of old distractors (Braithwaite \& Humphreys, 2003). In this case, inhibition might be applied to the color maps coding all the old items (both red and green in Experiment 7) and their locations. As a consequence, changes to any of the old stimuli would be sufficient to disrupt the preview benefit. However, this is inconsistent with the findings from Experiments 1-3. Here, we found that the addition of irrelevant green disks just before the second set of items in a preview display was equally ineffective at disrupting the preview benefit as the addition of red disks. However, if feature-based (green) inhibition of the preview distractors had been employed, the addition of new green distractors (disks) should have acted to reset the feature-based inhibition if they were sufficient in number (Braithwaite \& Humphreys, 2003; Watson \& Humphreys, 1998).

Relevant to this general issue, Kunar, Humphreys, and Smith (2003) have also recently shown that shape (but not color) changes to old preview items disrupt search in static displays (see also Watson \& Humphreys, 2002) but that the reverse holds for moving displays. Clearly, the exact role and flexibility of feature-based inhibition in stationary displays await future research.

\section{Ecological Validity of Feature-Based Versus Location-Based Inhibition}

We have presented evidence suggesting that the preview benefit arises from both inhibition of old stimuli, along with an anticipatory set for new stimuli. Our data suggest that this inhibition is based on a template representation that codes the locations of old items, irrespective of their features. According to our account, inhibition cannot be selectively applied to the locations of a subset of old items on the basis of a simple feature difference (i.e., an inhibitory template cannot be constructed for items of a particular color). Rather, it appears that inhibition is applied to all items currently in the field and that this is location based rather than feature based. In contrast, the anticipatory set for new stimuli appears to be based on the color of the new items. Why should inhibition of old items be location based, whereas anticipation of new stimuli is feature based?

The difference may reflect ecological pressures and optimizations. The locations of the appearance of anticipated new stimuli may generally be unknown, although their likely identities (and hence features) might be, for instance, awaiting the appearance of a particular type of predator (or prey). In this situation, the location of the new stimuli cannot be prioritized directly, but a selection advantage might be obtained by prioritizing the detection of their features. Thus, it is ecologically relevant to their detection. Thus, it is ecologically useful to be able to prioritize the features of new stimuli when they are known. In contrast, when old stimuli are known to be irrelevant, it may be more efficient to inhibit their locations rather than their features (unless they move; see Kunar, Humphreys, \& Smith, 2003; Watson \& Humphreys, 1998). This would have the advantage that newly appearing items that also share features with the old inhibited items would not themselves become inhibited or cause the old items to be disinhibited if the change in the inhibited feature map was sufficiently great (Watson \& Humphreys, 1997, 1998). One possible way to reconcile the present results with previous results showing a role for feature-based inhibition in stationary displays is that here the features of the target stimuli were known in advance, whereas in previous studies feature-based inhibition in stationary displays has been strongest when the identities of the new stimuli are unknown. It may be that in those situations, both location-based and featurebased inhibition of old stimuli are used to optimize selection.

\section{Implications for Alternative Accounts of the Preview Benefit}

Onset capture. Donk and Theeuwes (2001) have proposed that the preview benefit might be explained purely by the new items capturing attention automatically because they form abrupt onsets that are known to be able to capture attention automatically to some degree (e.g., Yantis \& Hillstrom, 1994; Yantis \& Johnson, 1990; Yantis \& Jones, 1991; Yantis \& Jonides, 1984). However, there are a number of reasons why automatic attention capture by new onsets cannot fully account for the whole set of data so far collected on the preview benefit. These are based on the time course and attentional capacity of automatic capture by abrupt onsets, probe dot effects, sensitivity to local luminance change, the differential effects of the modality of load tasks presented in the preview period, and effects of grouping between old and new items (for a summary, see Watson \& Humphreys, 2002, and Watson et al., 2003). The present data are also difficult to reconcile with a pure onset account of the preview benefit.

First, if observers were set to prioritize abrupt onsets, we would have expected a disruptive effect by the appearance of irrelevant onsets in Experiments 1-3. However, it might be argued that since the irrelevant onsets shared neither shape nor color with the search stimuli, then even if they captured attention, they may have had little impact on search performance as measured by search slopes. However, in Experiment 4 when the irrelevant items shared color with the new items, the preview ben- 
efit was disrupted but not abolished. This supports the possibility that observers were set to prioritize abrupt onsets of a specific color via an anticipatory set. However, if automatic capture by abrupt onsets is sufficient to explain the preview benefit, it is not clear why this would have led to an increase in search slope in the preview condition. This follows because even if the irrelevant blue disks and the new blue search items captured attention (because they were all blue onsets), search should have been no less efficient than when both blue disks and the blue search stimuli were presented simultaneously (and so should have captured attention simultaneously) in the single-feature baseline. Instead, the data are more consistent with the idea that attention capture by abrupt blue onsets drew resources away from the inhibitory marking of the old green items. This would then cause some of the old green distractors to recompete for selection with the blue search stimuli, thus increasing the preview search slope, relative to the singlefeature baseline.

Second, an onset account cannot explain why irrelevant onsets that appear at the start of the preview display and then disappear and reappear along with the new items reduced the preview benefit (Experiments 5-7). Again, if the reappearance of the irrelevant disks caused them to capture attention along with the new search items, search should be no less efficient than when the irrelevant disks appeared simultaneously along with the blue search items alone (i.e., in the corresponding single-feature baseline). Instead, the data are consistent with the development of an inhibitory template that represents all the items during the preview period. Dynamic changes to a sufficiently large subset of those items then feeds back to reduce the inhibition for all items coded by that template (see also Watson \& Humphreys, 1998, for a related finding with moving stimuli).

Temporal asynchrony account. Another account (Jiang et al., 2002) proposes that (at least with stationary stimuli) the preview benefit occurs because the visual system can individuate the old and new items into separate groups on the basis of their temporal asynchrony. Attention can then be applied to either group, depending upon task demands. This account also has some difficulty explaining the full set of marking results. For instance, it has difficulty explaining why some changes to old items are more effective at reducing the preview benefit than others (e.g., Watson \& Humphreys, 2002), the modality-dependent effects of load tasks (Humphreys, Watson, \& Jolicœur, 2002), and findings based on the probe dot paradigm (Olivers \& Humphreys, 2002; Watson \& Humphreys, 2000). The present data are also incompatible with the temporal asynchrony account. For instance, Experiments 1-4 showed that irrelevant onsets that appeared just before the second display disrupted the preview benefit only when they shared color with the new items. When they were the same color as the old items or different from all search stimuli, they had no im- pact on search performance. According to the temporal asynchrony account, all that matters is the difference in time between the old and the new items, and this was constant across all four experiments.

The findings from Experiments 5-7 are also likewise inconsistent with the temporal asynchrony account. Here, we found that irrelevant disks that appeared simultaneously with the old search items and then disappeared and reappeared with the new items disrupted the preview benefit. However, there was a large separation in time between the appearance of the old items and the disappearance of the disks and their reappearance with the new items. Thus, old and new items should have been sufficiently separated in time to allow their individuation on the basis of an asynchrony signal.

\section{Summary}

In summary, we have examined the effect of irrelevant abrupt onsets on the ability of observers to ignore a set of old stimuli in order to prioritize a subsequent set of stimuli (the preview benefit). We have shown that the appearance of irrelevant abrupt onsets just before the second set of stimuli reduces the preview benefit only when the onsets are the same color as the new stimuli. This is consistent with the adoption of a feature-based anticipatory set for new stimuli over and above any inhibition of old items (Braithwaite \& Humphreys, 2003). In contrast, changes to irrelevant items that were present from the outset of the preview display were found to disrupt the preview benefit whether or not they shared features with any other items in the display. This is consistent with all the old items being coded into an inhibitory template, irrespective of their features, that coordinates inhibition with respect to the locations of old items. Changes to those items can feed back to disrupt the inhibitory template and reduce the preview benefit. The data show that inhibition cannot be selectively applied to a subset of old items on the basis of a simple feature (color) difference between them, but rather operates in an all-or-none fashion in response to all the stimuli present at a given time.

\section{REFERENCES}

BaCON, W. F., \& EgEth, H. E. (1997). Goal-directed guidance of attention: Evidence from conjunctive visual search. Journal of Experimental Psychology: Human Perception \& Performance, 23, 948-961.

Braithwaite, J. J., \& Humphreys, G. W. (2003). Inhibition and anticipation in visual search: Evidence from effects of color foreknowledge on preview search. Perception \& Psychophysics, 65, 213-237.

Braithwaite, J. J., Humphreys, G. W., \& Hulleman, J. (2004) Probing distractor inhibition in preview search: Direct evidence for featurebased grouping from a luminance probe technique. Manuscript submitted for publication.

Chun, M. M., \& Wolfe, J. M. (1996). Just say no: How are visual searches terminated when there is no target present? Cognitive Psychology, 30, 39-78.

Donk, M., \& Theeuwes, J. (2001). Visual marking beside the mark: Prioritizing selection by abrupt onsets. Perception \& Psychophysics, 63, 891-900.

Downing, C. J., \& Pinker, S. (1985). The spatial structure of visual at- 
tention. In M. I. Posner \& O. S. M. Marin (Eds.), Attention and performance XI (pp. 171-188). Hillsdale, NJ: Erlbaum.

Duncan, J., \& HumphreYs, G. W. (1989). Visual search and stimulus similarity. Psychological Review, 96, 433-458.

DunCAN, J., \& HumphreYs, G. W. (1992). Beyond the search surface: Visual search and attentional engagement. Journal of Experimental Psychology: Human Perception \& Performance, 18, 578-588.

FolK, C. L., Remington, R. W., \& Johnston, J. C. (1992). Involuntary covert orienting is contingent on attentional control settings. Journal of Experimental Psychology: Human Perception \& Performance, 18, 1030-1044.

Folk, C. L., Remington, R. W., \& Wright, J. H. (1994). The structure of attentional control: Contingent attentional capture by apparent motion, abrupt onset, and color. Journal of Experimental Psychology: Human Perception \& Performance, 20, 317-329.

GiBson, B. S., \& JiANG, Y. [H.] (2001). Visual marking and the perception of salience in visual search. Perception \& Psychophysics, 63, 5973.

Humphreys, G. W., Jung-Stalmann, B., \& Olivers, C. N. L. (2004). An analysis of the time course of attention in preview search. Perception \& Psychophysics, 66, 713-730.

Humphreys, G. W., \& Müller, H. J. (1993). Search via recursive rejection (SERR): A connectionist model of visual search. Cognitive Psychology, 25, 43-110.

Humphreys, G. W., RidDoch, M. J., Nys, G., \& Heinke, D. (2002). Transient binding by time: Neuropsychological evidence from antiextinction. Cognitive Psychology, 19, 361-380.

Humphreys, G. W., Watson, D. G., \& Jolicceur, P. (2002). Fractionating the preview benefit in search: Dual-task decomposition of visual marking by timing and modality. Journal of Experimental Psychology: Human Perception \& Performance, 38, 640-660.

JiANG, Y. H., ChUn, M. M., \& MarKs, L. E. (2002). Visual marking: Selective attention to asynchronous temporal groups. Journal of Experimental Psychology: Human Perception \& Performance, 28, 717 730.

Kunar, M., Humphreys, G. W., \& SMith, K. J. (2003). Visual change with moving displays: More evidence for color feature map inhibition during preview search. Journal of Experimental Psychology: Human Perception \& Performance, 29, 779-792.

Kunar, M., Smith, K. J., Humphreys, G. W., \& Watson, D. G. (2003). When a re-appearance is old news: Visual marking survives occlusion. Journal of Experimental Psychology: Human Perception \& Performance, 29, 185-198.

MACK, A., \& Rock, I. (1998). Inattentional blindness. MIT Press.

Olivers, C. N. L., Braithwaite, J., \& HumphreYs, G. W. (2002). Why are responses to new targets delayed when new is prioritized? Response suppression effects in the preview paradigm. Unpublished manuscript.

Olivers, C. N. L., \& Humphreys, G. W. (2002). When visual marking meets the attentional blink: More evidence for top-down, limitedcapacity inhibition. Journal of Experimental Psychology: Human Perception \& Performance, 28, 22-42.

Olivers, C. N. L., \& Humphreys, G. W. (2003). Visual marking and singleton capture: Fractionating the unitary nature of visual selection. Cognitive Psychology, 47, 1-42.

O’Regan, J. K., Rensink, R. A., Clark, J. J. (1999). Change-blindness as a result of "mudsplashes." Nature, 398, 34.

Posner, M. I., \& Boles, S. J. (1971). Components of attention. Psychological Review, 78, 391-408.

Rensink, R. A. (2000). The dynamic representation of scenes. Visual Cognition, 7, 17-42

Simons, D. J. (1996). In sight, out of mind: When object representations fail. Psychological Science, 7, 301-305.

Simons, D. J., \& Levin, D. T. (1997). Change blindness. Trends in Cognitive Sciences, 1, 261-267.

Simons, D. J., \& LeVIN, D. T. (1998). Failure to detect changes to peo- ple during a real-world interaction. Psychonomic Bulletin \& Review, 5, 644-649.

Theeuwes, J., Kramer, A. F., Hahn, S., \& Irwin, D. E. (1998). Our eyes do not always go where we want them to go: Capture of the eyes by new objects. Psychological Science, 9, 379-385.

Treisman, A. M., \& Gelade, G. (1980). A feature-integration theory of attention. Cognitive Psychology, 12, 97-136.

Watson, D. G. (2001). Visual marking in moving displays: Featurebased inhibition is not necessary. Perception \& Psychophysics, 63, 74-84.

Watson, D. G., \& Humphreys, G. W. (1997). Visual marking: Prioritizing selection for new objects by top-down attentional inhibition. Psychological Review, 104, 90-122.

WATSON, D. G., \& HuMPhreys, G. W. (1998). Visual marking of moving objects: A role for top-down feature-based inhibition in selection. Journal of Experimental Psychology: Human Perception \& Performance, 24, 946-962.

Watson, D. G., \& Humphreys, G. W. (2000). Visual marking: Evidence for inhibition using a probe-dot detection paradigm. Perception \& Psychophysics, 62, 471-481.

Watson, D. G., \& Humphreys, G. W. (2002). Visual marking and visual change. Journal of Experimental Psychology: Human Perception \& Performance, 28, 379-395.

Watson, D. G., Humphreys, G. W., \& Olivers, C. N. L. (2003). Visual marking: Using time in visual selection. Trends in Cognitive Sciences, 7, 180-186.

Wolfe, J. M. (1998). Visual search. In H. Pashler (Ed.), Attention (pp. 13-74). Hove, U.K.: Psychology Press.

Yantis, S., \& Gibson, B. S. (1994). Object continuity in apparent motion and attention. Canadian Journal of Experimental Psychology, 48, 182-204.

Yantis, S., \& Hillstrom, A. P. (1994). Stimulus-driven attentional capture: Evidence from equiluminant visual objects. Journal of Experimental Psychology: Human Perception \& Performance, 20, 95107.

YAnTIS, S., \& Johnson, D. N. (1990). Mechanisms of attentional priority. Journal of Experimental Psychology: Human Perception \& Performance, 16, 812-825.

YANTIS, S., \& JoNES, E. (1991). Mechanisms of attentional selection: Temporally modulated priority tags. Perception \& Psychophysics, 50, 166-178.

YANTIS, S., \& Jonides, J. (1984). Abrupt visual onsets and selective attention: Evidence from visual search. Journal of Experimental Psychology: Human Perception \& Performance, 10, 601-621.

\section{NOTE}

1. Often observed is an increase in overall RTs in the preview condition compared with the single-feature baseline even though there may be no difference in search slope. Watson and Humphreys (1997) speculated that this might be caused either by a reduction in arousal (Posner $\&$ Boies, 1971) during the preview interval or because the commitment of attentional resources to the task of ignoring the old items resulted in a delayed onset of search through the new items when they arrived. The overall difference in RTs was still present even when differential effects of arousal were controlled for, supporting the latter hypothesis (Watson \& Humphreys, 1997). More recent work has shown that a general increase in RTs may also be caused by a residual response inhibition to the onset of the first set of stimuli (which must not be responded to). When the first stimuli were added via a gradual onset rather than an abrupt onset (which would require a greater effort to resist responding to), the overall RT difference between the single-feature and preview conditions was reduced (Olivers, Braithwaite, \& Humphreys, 2002).

(Manuscript received September 15, 2003; revision accepted for publication May 15, 2004. 